East African Medical Journal Vol. 81 No. 5 May 2004

SCHISTOSOMA MANSONI OF THE CONUS MEDULARIS: CASE REPORT

P. K., Wanyoike, MBChB, MMed(Surg) Consultant General Surgeon and Senior Neurosurgery Registrar and M. M., Qureshi, MBChB, MMed(Surg), FRCSED(SN), Consultant Neurosurgeon and Head of Neurosurgery, Kenyatta National Hospital, P.O Box 20723, Nairobi, Kenya

Request for reprints to: Dr. P.K. Wanyoike, Kenyatta National Hospital, P.O Box 20723, Nairobi, Kenya

\title{
SCHISTOSOMA MANSONI OF THE CONUS MEDULARIS: CASE REPORT
}

\author{
P. K. WANYOIKE and M. M. QURESHI
}

\begin{abstract}
SUMMARY
A six year old girl was admitted to the Kenyatta National Hospital paediatric unit with history of headaches, fever, neck stiffness and paraesthesias of the lower limbs. She was empirically commenced on antimeningitic treatment. Her neurological state deteriorated over a period of two months to paraparesis and paraplegia of the lower limbs with urinary and stool incontinence. A neurology review revealed a sensory level at T10 with power grade 2 in the lower limbs. A myelogram revealed a block of contrast at T12. An impression of cord compression by an intraspinal tumour was made. Laminectomy and posterior midline myelotomy was performed. At operation a greyish - white intramedullary mass lesion was found. Histology revealed a schistosoma mansoni ovum surrounded by granulomatous tissue with giant cells and polymorphoneuclear leucocytes. The child was commenced on paziquantel $1000 \mathrm{mg}$ and dexamethasone $24 \mathrm{mg}$ per day in divided doses. There was marked neurological improvement and the patient went home one month later. She was able to walk without support and was continent of urine and stool at the time of discharge.
\end{abstract}

\section{INTRODUCTION}

Schistosomiasis of the nervous system is a rare condition with only about 67 cases reported in the world literature to date. Upto 1985 only 52 cases were reported in the world literature(1). Ruberti et al. have reported five cases $(2,3)$ while recently, five cases have been reported from South Africa, three from Egypt and two from Uganda(4).

Schistosoma mansoni is the most common cause of spinal schistosomiasis worldwide(5), although, $S$. haematobium has been isolated(6). In Brazil, 3-4 million people are infected and 30 million are exposed(7). In Kenya schistosomiasis is endemic especially along the coastal belt and lake Victoria regions(8-12).

Schistosoma mansoni eggs were first reported in the spinal cord of a patient who lived in Brazil in 1930 by Muller and Stender(13). However the first case of spinal schistosomiasis was reported in 1905 by Matumura and Tsunoda in a patient with transverse myelitis due to $S$. japonicum. The diagnosis of this disease is based on evidence of low thoracic/upper lumbar neurological symptoms, demonstration of schistosomal infection by microscopic or serologic techniques, and exclusion of other causes of transverse myelitis(14).

Our case report is the first one reported from a slum area in Nairobi, the capital of Kenya. It highlights the need to include schistosomiasis in the differential diagnosis of mass lesions causing cord compression. Schistosoma mansoni has a predilection for the lower thoracic and upper lumber spine T12-Ll(15).The mode of spread to the spinal cord is thought to be through pulmonary arteriovenous shunts and vertebral venous plexus. The venous plexus of Batson between the pelvic and vertebral venous plexus offers an ideal route of spread as its valveless (16). The pathophysiology is poorly understood but is considered to be a delayed hypersensitivity type of reaction by the glial cells of nervous system to the egg of $S$. mansoni $(17,18)$.

\section{CASE REPORT}

A six year old girl from Kibera, a slum area within Nairobi was admitted to Kenyatta National Teaching and Referral Hospital in August 2003. She gave a history of sudden onset of headaches, neck stiffness, fever and paraesthesias of the lower limbs. An initial diagnosis of pyogenic meningitis was made and the child commenced empirically on antimeningitic treatment. While in the ward the neurological condition deteriorated with paraparesis progressing to paraplegia and loss of deep tendon reflexes in both lower limbs within a week of admission. She also developed urinary and stool incontinence. On examination she was found to have neck stiffness, a sensory level at T10 and power grade 2 in the lower limbs.

Investigations carried out included a haemogram, which revealed a normal white cell count with a lymphocyte count of $35 \%$ neutrophils of $65 \%$ and an ESR of $16 \mathrm{~mm} / \mathrm{hr}$. A conventional myelogram revealed a complete block of contrast at T12 due to an expansile mass lesion of the conus medularis (Figure 1). 
Figure 1

Conventional myelogram showing complete cut-off of contrast at $T 12$

A chest X-ray and a plain lumbar spine X-ray were reported as normal.

On the basis of deteriorating neurological signs and myelogram findings, neurosurgical opinion was sought. Urgent surgical intervention was advised. The child was commenced on intravenous high dose dexamethasone of $8 \mathrm{mg}$ three times a day.

Laminectomy of T11-L1 was carried out and the cord found expanded at the level of the conus medularis. Durotomy revealed an expanded conus medularis completely filling the spinal canal with residual contrast distal to the expansion. Posterior midline myelotomy was performed using bipolar coagulation, and micro surgical dissection. A grayish/white lesion was found at the center of the cord. Gentle excision using micro pituitary ronguers was carried out piecemeal until all the macroscopic tumour was removed. Dural closure was achieved using 3/0 vicryl suture.

\section{RESULTS}

The patient was continued on high dose dexamethasone at $24 \mathrm{mg} /$ day. Marked neurological improvement occurred in the sensory level within the first week post- operatively. Histopathological results revealed a granulomatous lesion with langhans and foreign body type giant cells surrounding ova of S. mansoni(Figure 2).
Figure 2

Ova of S. mansoni surrounded by granulomatous tissue and foreign body type giant cells

The child was also commenced on praziquantel $1000 \mathrm{mg}$ and continued on dexamethasone $24 \mathrm{mg}$ per day. Two months later she had recovered her sensation and the power in the lower limbs. She had also regained continence of urine and stools. She was able to walk unsurported at time of discharge. She maintained steady progress at follow-up reviews.

\section{DISCUSSION}

The rapid improvement in neurological symptoms following surgery is probably attributable to the decompression of the cord and the high dose dexamethasone (24mg/ day first week post-op). Praziquantel $1000 \mathrm{mg}$ was added during the second week. Oxamniquine, which is specific for S. mansoni, is no longer in production as a result of its side effects

An intraoperative diagnosis of a probable glioma was entertained in view of the appearance at surgery. The diagnosis of schistosomiasis is based on the history of exposure in an endemic region, the demonstration of eggs in the stool, urine or rectal snipes, the presence of oesinophilia in peripheral blood and the possitivity of serological tests haemaglutination, ELISA, IgG and IgM. Conventional myelography remains the gold standard in demonstrating the level of a mass lesion in spinal cord compression. MRI and CT scanning of the nervous system with contrast in suspected schistosomial myeloradiculopathy have reported typical lesions(19). 
Schistosomiasis is endemic in parts of Kenya particularly the coastal belt and the lake region (8-12). It is also to be found in areas that undertake irrigation projects like Mwea, Machakos and the Nyando basin. $S$. mansoni and $S$. haematobium are the commonest species in the East African region. The principal intermediate hosts are the Biomphararia and Bulinus snails respectively. Kibera slum area is next to Nairobi dam whose waters have been rendered stagnant by the presence of water hyacinth. Coupled with the poor hygienic and sanitary conditions, the area is ripe for an endemic status categorization. The situation is made worse by the fact that the molusccide treatment programme halted in the 1980s. It is therefore likely that there is a resurgence of schistosomiasis. The prevalence of schistosomiasis in this urban setting needs to be assessed in order to document the extent of the problem and offer the necessary preventive measures.

\section{CONCLUSION}

Schistosomal myeloradiculopathy should be considered in patients presenting with cord compression or features of transverse myelitis especially in patients from endemic areas or low social economic settlements. Diagnosis from cerebrospinal fluid studies and stool/ rectal biopsy might obviate the need for surgery especially in transverse myelitis. However in deteriorating neurological conditions, urgent surgical intervention followed by anti-schistosomal drug therapy remains the treatment of choice.

\section{ACKNOWLEDGEMENTS}

To the Director, Kenyatta National Hospital for permission to publish the paper. To Dr. M. H. Wandie and the staff of ward 3D for looking after the patient and Dr A. K. Gachie and Dr. Odhiambo for the histopathological and radiological interpretations.

\section{REFERENCES}

1. Schrimgeour, E. M., and Gajdusek, D. C., Involvement of the central nervous system in schistosomal mansoni and S. haematobium infection. Brain. 1985; 108:1023-1038.

2. Ruberti, R. F., and Saio, M., Schistosomiasis of the spinal cord. Afr. J. Neurol. Sci.1994; 13: 25-28.
3. Ruberti, R. F., and Chopra, S. A., Schistosomiasis of the spinal cord. Medicine d'Afrique Noire.1976; 23:77-81.

4. Owuor, G., Korev, A., Ssenyonjo, H. and Kiryabwire, J., Schistosomiasis of the spinal cord: Report of two cases. East Afr. Med. J. 2001; 78: 49-51.

5. Elkayat, R. A., and Girgis, M., Bilharzial granuloma of the conus; case report. Neurosurgery. 1993; 32:1022-1024.

6. Cosnett, J. E., and Van Deled, J. R., Schistosomiasis (Bilhazia) of the spinal Cord: case reports and clinical profile. Quart. J. Med. 1986; 61: 1131-1139.

7. Amaral, R. S., and Porto, M. A. S. Evolucao e situacao atualdo controle da esquitosomose no Brasil. Bras. Med. Trop. 1994; 27(sup.iii): 73-90.

8. WHO. The control of schistosomiasis. Second report of the WHO Expert committee. Geneva. WHO Technical committee report series no. 830, 1993.

9. Doumenge, J. P., Mott, K. E., Cheung, C., et al. Atlas of the global distribution of schistosomiasis. Kenya CEGET - CNRS/OMS-WHO. 249,1987.

10. Smith, D. H., Warrens, K. S., and Mahamoud, A. A., Morbidity in schistosomiasis mansoni in relation to intensity of infection: study of a community in Kisumu, Kenya. Amer. J. trop. Med. Hyg. 1979; 28:220-229.

11. Chunge, R. N., Karumba, P. N., Nalgelkerke, N., et al. Intestinal parasites in a rural community in Kenya. Cross sectional surveys with emphasis on prevalence, incidence, duration of infection, and polyparasitism. East Afr. Med.J. 1991; 68:112-123.

12. Chunge, R. N., Karumba, P. N., Ouma, J. H., Thiong'o, F.W. et al. Polyparasitism in two rural communities with endemic schistosoma mansoni infections in Machakos District, Kenya. J. trop. Med. Hyg. 1995; 98:440-444.

13. H. R., Muller, and Stender, A. Bilharziose desRuckemrkes unter dem Bilde einer myelitisdorso-lumtransversa completa. Arch. f. Schiffs U. Tropen-hyg 1930; 34:527-538.

14. Centers for Disease control and prevention. Acute transverse myelitis in students returning from Kenya (Editorial note). Morb. Mortal Wkly Rep. 1984; 33: 446-447.

15. Ruberti, R. F, and Saio, M. Epidural Bilharzioma Mansoni compressing the spinal cord: case report. East Afr. Med. J. 1999; 76:414-416.

16. Batson, O. V., The function of the vertebral veins and their role in the spread of metastases. Ann. Surg. 1940; 112:138-149.

17. Pittela, J. E. H., Gusmao, S. N., Cavalho, G. T., Silveila, R. L., and Campos G. L. Tumoral form of cerebral schistosomiasis mansoni: A report of 4 cases and a review of the literature. Clinic neurosurg.

18. Pittela, G. E. H. Neuroschistosomiasis. Brain Pathol. 1997; 7:649-662.

19. Bennet, G., and Provenzale, J. M., Schistosomal myelitis: findings at MR Imaging. Eur. J. Radiol. 1998; 27:268-270. 